\title{
Liderança situacional em gestão de projetos: uma revisão da literatura
}

\author{
Helen Silva Gonçalves ${ }^{\mathrm{a}, *}$, Caroline Maria de Miranda Mota ${ }^{\mathrm{b}}$ \\ a,*helenmep@hotmail.com, UFPB, Brasil \\ ${ }^{\mathrm{b}}$ mota.cmm@gmail.com, UFPE, Brasil
}

\begin{abstract}
Resumo
0 estilo de liderança que deve ser adotado por um gerente de projetos em relação a seus liderados é um assunto enfatizado em pesquisas recentes. Dentre as teorias, a liderança situacional apresentada por Hersey e Blanchard (2007) aborda as maturidades para o trabalho e psicológica como elementos que influenciam o desempenho dos funcionários. A determinação de tal nível permite a utilização de um estilo de liderança mais adequado. Este artigo aborda a necessidade de utilização de uma ferramenta que auxilie de maneira eficiente o gerente de projetos a adotar o estilo de liderança mais adequado à situação e liderados. Para demonstrar o qual difícil pode ser tal atividade, em uma empresa de tecnologia da informação, foi realizada uma pesquisa avaliando o nível de maturidade de seus liderados. Observou-se que para a liderança ser mais efetiva deve dispor de métodos mais estruturados para tal.

Palavras-chave

Estilo de liderança. Liderança situacional. Gerente de projetos.
\end{abstract}

\section{Introdução}

Mudanças no mundo dos negócios e das organizações requerem reavaliações de algumas questões, dentre elas o papel da liderança. Segundo Soto (2002), para atender às novas exigências, compete aos líderes conhecer e transformar a organização dentro de uma dinâmica competitiva de esforço, adaptação, desafios e mudança constante.

A liderança tem papel fundamental nas relações humanas, a capacidade de liderar associa-se ao sucesso ou fracasso das organizações. Alguns artigos abordam as características, habilidades ou competências importantes no líder em função de um estilo de liderança a ser adotado, ou abordam, em razão desses aspectos, qual liderança está sendo utilizada de fato (DULEWICZ; HIGGS, 2003; MULLER; TURNER, 2005, 2007 DULAIMI; LANGFORD, 1999). Quando se consideram ambientes específicos para o desenvolvimento da liderança, como a área de gestão de projetos, por exemplo, tem que se ponderar as especificidades relacionadas, como área de atuação e complexidade, que tratam de resultados específicos.
A preocupação com o papel do gerente de projetos no gerenciamento de projetos é cada vez maior, em como ele deve proceder com relação a uma tarefa a ser realizada em função das características específicas do projeto, em como deve proceder em relação aos indivíduos ou grupo do projeto.

Muller e Turner (2007), em pesquisa sobre sucesso do projeto através do estilo de liderança do gerente e diferentes estilos para tipos distintos de projeto, confirmaram que as competências da liderança desenvolvidas pelos gerentes estavam correlacionadas com o sucesso do projeto quanto a custo, prazo e tempo, e que estilos de liderança variados seriam adequados a diferentes tipos de projetos.

Um elemento que se apresenta como oportunidade de estudo se refere a como os liderados podem ser avaliados em termos de preparação, ou maturidade, como os autores Hersey e Blanchard (2007) a denominam, para realização das atividades. Quando se fala em líder, fala-se também em liderados e tarefas. São três variáveis 
interdependentes. Em função da tarefa a ser realizada, seu grau de complexidade, importância, tempo, a pessoa ou grupo responsável deverá apresentar um comportamento ou maturidade específica. Para isso, o papel do líder é de fundamental importância no que se refere à manutenção de um nível de maturidade ou passagem para outro.

A flexibilidade em adaptação é extremamente importante na área de gestão de projetos, que exige mais do gerente em termos de dedicação ou habilidade para lidar com as pessoas na realização das tarefas.

Neste artigo se apresenta um importante instrumento que auxilia o gerente de projetos a verificar o nível de maturidade de seus liderados antes de adotar o estilo de liderança adequado em determinada situação ou etapa do projeto. Para tal, realizou-se uma breve revisão da literatura da área de liderança e sua relação com projetos, e foi realizada também uma pesquisa através de questionários junto a gerente e liderados de uma empresa de tecnologia da informação, para demonstrar a dificuldade que avaliar individualmente cada liderado representa. A pesquisa evidenciou a necessidade desse instrumento de apoio à definição de estilos de liderança a ser adotados.

\section{Lideranças: aspectos gerais}

Segundo Luthans (2005), não obstante toda a atenção dada à liderança, ainda há controvérsia. É sabido que existe e têm influência no desempenho humano, mas seu funcionamento e dimensões específicas não são precisamente definidos. Contudo, a definição específica de liderança não é importante, e sim interpretá-la em termos de enquadramento teórico e específico para perceber que a liderança faz diferença.

Apesar de algumas definições específicas, a maioria depende da orientação teórica considerada. Além da influência, a liderança tem sido definida em termos de processo grupal, personalidade, respeito, comportamentos específicos, persuasão, poder, conquista de meta, interação, diferenciação, o início da estrutura, e combinações destes.

Hersey e Blanchard (2007) definem a liderança como o processo de influenciar as atividades dos indivíduos ou grupos para a consecução de um objetivo em uma situação. Uma definição de liderança que capta a essência de suas características é a de Weathersby (1999), para quem a liderança centra-se na criação de uma visão comum. Significa motivar as pessoas a contribuir para a visão e encorajá-los a alinhar os seus próprios interesses com os da organização.
Existem bases teóricas distintas para a liderança. Inicialmente, a teoria da liderança implicava em alguns indivíduos que nasciam com determinadas características que lhes permitiam serem líderes, conhecida como a teoria de traços de liderança, conforme Quadro 1 (MONTANA; CHARNOV, 2003). Insatisfeito com esta abordagem, pesquisadores mudaram a ênfase do indivíduo para o líder do grupo. A liderança vista em termos de comportamento do líder e em como este afetava e era afetado pelo grupo de seguidores (LUTHANS, 2005).

Além do líder e do grupo, o contexto começou a receber maior atenção da teoria da liderança. 0 líder passou a ser visto como um produto dos tempos e da situação. Como base teórica para a liderança, esta perspectiva teve muito prestígio histórico, servindo de base para teorias de liderança situacional, ou contingencial. A teoria situacional chamada de caminho-meta é uma tentativa de sintetizar conceitos motivacionais e liderança. Essas teorias são conhecidas como as teorias de liderança tradicionais (BERGAMINI, 1999; KOUZES; POSNER, 2007).

É importante ressaltar que a abordagem situacional vem abrindo espaço também para uma nova perspectiva chamada teoria ou escola neocarismática (Quadro 1). Os estudos sobre liderança têm na liderança transformacional um novo paradigma, porque na nova configuração mundial o nível de necessidade humana tem aumentado (ROBBINS, 2005; MULLER; TURNER, 2005; KEEGAN; HARTOG, 2004).

Contudo, o líder deve ter o correto discernimento de saber quanto de suporte ao relacionamento deve ser dado ao liderado, pois o foco no que deve ser feito, a tarefa a ser realizada sempre irá existir. E para que seja possível o desenvolvimento de um estilo de liderança nas bases da transformacional se faz necessário contar com liderados que saibam quais são suas atribuições básicas, as cumpram e possam então buscar novas formas desafiadoras de execução.

Outras duas escolas consideradas foram as da inteligência emocional e de competência, onde consideravam, respectivamente, que a inteligência emocional tem maior impacto sobre o sucesso do líder, e que era importante identificar as competências efetivas do líder (MULLER; TURNER, 2005).

A evolução dessas teorias pode ser visualizada no Quadro 1.

Pensar no que caracteriza a liderança, quais aspectos importantes devem ser avaliados no líder, é algo complexo, pois estes muitas vezes são subjetivos, difíceis de serem medidos e difícil definir níveis adequados de atingimento. Dulewicz e Higgs (2003) identificaram 15 competências que 
Quadro 1. Evolução das principais teorias de liderança.

\begin{tabular}{|c|c|c|c|}
\hline Teorias & Foco & Aspectos da liderança & Caracteristicas \\
\hline $\begin{array}{l}\text { Teoria dos traços } \\
\text { de liderança } \\
\text { Montana e } \\
\text { Charnov (2003) }\end{array}$ & $\begin{array}{c}\text { Enfatiza de forma especial as } \\
\text { qualidades pessoais do líder; } \\
\text { determinadas características de } \\
\text { personalidade. }\end{array}$ & $\begin{array}{l}\text { Avalia os fatores físicos: altura, peso, físico, } \\
\text { aparência e idade; avalia as habilidades: } \\
\text { inteligência, fluência verbal, escolaridade } \\
\text { e conhecimento; avalia aspectos de } \\
\text { personalidade: moderação, introversão, } \\
\text { extroversão, dominância, ajustamento } \\
\text { pessoal, autoconfiança, sensibilidade } \\
\text { interpessoal e controle emocional. }\end{array}$ & $\begin{array}{l}\text { A dificuldade final com esse tipo de } \\
\text { abordagem para o entendimento da } \\
\text { liderança é que, sendo uma teoria } \\
\text { baseada na genética, ela não assume } \\
\text { que as características são aprendidas. }\end{array}$ \\
\hline $\begin{array}{l}\text { Teoria da abordagem } \\
\text { comportamental } \\
\text { Luthans (2005) }\end{array}$ & $\begin{array}{l}\text { Enfatiza que a liderança pode } \\
\text { ser aprendida por meio de } \\
\text { técnicas de desenvolvimento } \\
\text { pessoal. }\end{array}$ & $\begin{array}{l}\text { Liderança autocrática - uma orientação } \\
\text { intensa à produção, as atividades do líder } \\
\text { estão ligadas a coisas; estilo democrático } \\
\text { - uma orientação aos funcionários, } \\
\text { envolvendo pessoas; estilo liberal - o líder } \\
\text { delega totalmente as decisões ao grupo e } \\
\text { deixá-os à vontade e sem controle algum. }\end{array}$ & $\begin{array}{c}\text { O foco dessa abordagem ao } \\
\text { comportamento de liderança } \\
\text { proporcionou uma percepção } \\
\text { verdadeira das origens e eficácia } \\
\text { da liderança, mas sua procura pelo } \\
\text { melhor estilo de liderança é um } \\
\text { ponto fraco. }\end{array}$ \\
\hline $\begin{array}{l}\text { Abordagem de } \\
\text { Blake e Mouton }\end{array}$ & $\begin{array}{l}\text { Estes autores desenvolveram } \\
\text { uma teoria que flexibiliza } \\
\text { fatores relacionados a pessoas } \\
\text { ou tarefas, a "grade gerencial” } \\
\text { (Managerial Grid). }\end{array}$ & $\begin{array}{l}\text { Identificaram cinco estilos de liderança } \\
\text { baseados em suas preocupações (pessoas } \\
\text { e produção); eles propuseram uma } \\
\text { grade gerencial, para que fosse possível } \\
\text { enquadrar os estilos de liderança. }\end{array}$ & $\begin{array}{l}\text { Por ser um modelo que mede os } \\
\text { valores e atitudes de um gerente, } \\
\text { pode ser bastante subjetivo, difícil } \\
\text { de medir e mudar os estilos. }\end{array}$ \\
\hline \begin{tabular}{|c|} 
Teoria da abordagem \\
contingencial ou \\
situacional \\
Kouzes e Posner \\
(2007); Hersey e \\
Blanchard (2007)
\end{tabular} & $\begin{array}{l}\text { Passa a visualizar como } \\
\text { a liderança realmente } \\
\text { flui, deixando de lado os } \\
\text { comportamentos dos líderes, } \\
\text { surgindo a figura dos } \\
\text { seguidores e seus anseios em } \\
\text { relação ao estilo de liderança } \\
\text { adotado. }\end{array}$ & $\begin{array}{l}\text { Há distinção prévia entre a orientação } \\
\text { às tarefas e aos empregados e assinala } \\
\text { que o estilo de liderança mais apropriado } \\
\text { depende da situação geral. Critérios: } \\
\text { líderes - a autoridade formal e } \\
\text { personalidades; seguidores - com suas } \\
\text { expectativas e interesses; situação - com } \\
\text { suas relevâncias e emergências. }\end{array}$ & $\begin{array}{l}\text { A abordagem situacional torna-se } \\
\text { atraente por considerar tais critérios. } \\
\text { Porém, o exercício da liderança } \\
\text { exige, também, uma constante } \\
\text { busca de autoconhecimento e de } \\
\text { autodesenvolvimento de um líder. }\end{array}$ \\
\hline $\begin{array}{l}\text { Abordagem de } \\
\text { Fiedler }\end{array}$ & $\begin{array}{l}\text { Postula que a efetividade da } \\
\text { liderança depende do estilo de } \\
\text { interação com as pessoas e da } \\
\text { favorabilidade da situação. }\end{array}$ & $\begin{array}{l}\text { Seu modelo propunha que o estilo de } \\
\text { liderança (orientado a tarefa ou pessoa) é } \\
\text { uma característica relativamente estável da } \\
\text { personalidade; que a situação pode ser mais } \\
\text { ou menos favorável na influência do líder } \\
\text { sobre os subordinados; e que a efetividade } \\
\text { da liderança é um produto desses dois. }\end{array}$ & $\begin{array}{l}0 \text { modelo de Fiedler foi um dos } \\
\text { primeiros avanços nestes estudos, } \\
\text { por apresentar um modelo que } \\
\text { associava elementos situacionais aos } \\
\text { aspectos da eficácia da liderança. }\end{array}$ \\
\hline $\begin{array}{l}\text { Abordagem do } \\
\text { Path-goal }\end{array}$ & $\begin{array}{c}\text { Realça para além da } \\
\text { importância da situação as } \\
\text { necessidades e objetivos dos } \\
\text { subordinados. }\end{array}$ & $\begin{array}{l}\text { A função motivacional do líder é } \\
\text { recompensar os subordinados pelos } \\
\text { alcances dos objetivos, facilitando } \\
\text { esse caminho por meio de progresso, } \\
\text { esclarecendo dúvidas, reduzindo entraves, } \\
\text { aumentando as oportunidades para } \\
\text { satisfação pessoal nessa trajetória. }\end{array}$ & $\begin{array}{l}\text { Devido o foco da abordagem } \\
\text { priorizar os objetivos pessoais dos } \\
\text { membros e suas percepções dos } \\
\text { objetivos organizacionais, além do } \\
\text { caminho mais efetivo para o alcance } \\
\text { desses, foi considerado uma novidade } \\
\text { em relação ao modelo de Fiedler. }\end{array}$ \\
\hline $\begin{array}{c}\text { Abordagem } \\
\text { situacional de } \\
\text { Hersey e Blanchard }\end{array}$ & $\begin{array}{l}\text { Nesse modelo a liderança } \\
\text { bem-sucedida é alcançada pela } \\
\text { escolha do estilo adequado, } \\
\text { relacionado ao nível de } \\
\text { prontidão dos liderados, sendo, } \\
\text { portanto uma teoria com foco } \\
\text { central nos liderados. }\end{array}$ & $\begin{array}{l}\text { O líder desenvolve a capacidade de } \\
\text { diagnosticar a situação dos seus liderados } \\
\text { em termos de maturidade para realizar a } \\
\text { tarefa e de se posicionar enquanto líder. }\end{array}$ & $\begin{array}{l}\text { Este modelo conquistou diversos } \\
\text { especialistas, sendo bastante } \\
\text { aplicado para o desenvolvimento } \\
\text { de líderes. Em função de algumas } \\
\text { críticas, os autores afirmam tratar-se } \\
\text { de um modelo prático e não de uma } \\
\text { teoria. }\end{array}$ \\
\hline $\begin{array}{c}\text { Teorias } \\
\text { neocarismáticas } \\
\text { ou visionárias } \\
\text { Robbins (2005); } \\
\text { Muller e Turner } \\
\text { (2005) }\end{array}$ & $\begin{array}{l}\text { Enfatizam o simbolismo, } \\
\text { o apelo emocional e o } \\
\text { compromisso por parte dos } \\
\text { liderados. Os seguidores } \\
\text { atribuem ao líder capacidades } \\
\text { heroicas e comportamentos que } \\
\text { os diferenciam dos demais. }\end{array}$ & $\begin{array}{l}\text { Dois tipos de líderes: aqueles que se } \\
\text { concentram em seus relacionamentos e } \\
\text { em comunicar valores e aqueles que se } \\
\text { concentram no processo. São chamados de } \\
\text { líderes transformacionais e transacionais, } \\
\text { respectivamente. }\end{array}$ & $\begin{array}{c}\text { A liderança carismática nem sempre } \\
\text { é necessáriá para se atingir altos } \\
\text { níveis de desempenho. }\end{array}$ \\
\hline \begin{tabular}{|} 
Escola da inteligência \\
emocional \\
Muller e Turner \\
(2005)
\end{tabular} & $\begin{array}{l}\text { Inteligência emocional tem um } \\
\text { impacto maior no desempenho } \\
\text { do que no intelecto. }\end{array}$ & $\begin{array}{l}\text { Esta escola assume que todos os gerentes } \\
\text { têm um razoável nivel de inteligência. } 0 \\
\text { que diferencia os seus dirigentes não é } \\
\text { inteligência, mas a sua resposta emocional } \\
\text { a situações. }\end{array}$ & $\begin{array}{l}\text { Inteligência emocional do gerente } \\
\text { afeta a sua percepção de sucesso. }\end{array}$ \\
\hline $\begin{array}{c}\text { Escola da } \\
\text { competência } \\
\text { Dulewicz e Higgs } \\
(2005)\end{array}$ & $\begin{array}{c}\text { Diferentes combinações de } \\
\text { competências podem levar a } \\
\text { diferentes estilos de liderança, } \\
\text { adequados em circunstâncias } \\
\text { diferentes. }\end{array}$ & $\begin{array}{c}\text { Líderes eficazes apresentam certas } \\
\text { competências, incluindo características, } \\
\text { comportamentos e estilos; emoções, } \\
\text { processo, intelecto. }\end{array}$ & $\begin{array}{c}\text { Diferentes perfis de competência são } \\
\text { melhores em situações diferentes, } \\
\text { produzindo líderes transacionais em } \\
\text { situações de baixa complexidade e } \\
\text { transformacionais em situações de } \\
\text { alta complexidade. }\end{array}$ \\
\hline
\end{tabular}


influenciam o desempenho da liderança, agrupadas em três tipos de competências, chamadas de intelectual (Intellectual Qualification), de gestão (Managerial Qualification) e emocional (Emotional Qualification). No Quadro 2 vê-se cada grupo e suas competências.

A competência intelectual (QI) seria responsável por $27 \%$ do desempenho da liderança, a gerencial (MQ), por 16\%, e a emocional (EQ), por 36\%. Competência emocional seria a mais significativa, embora as outras duas sejam importantes também.

Goleman, Boyatzis e Mckee (2003), por sua vez, identificam 19 competências de liderança agrupadas em quatro dimensões:

- Competências pessoais.

1. Autoconhecimento;

2. Autogestão.

- Competências sociais.

3. Consciência social;

4. Relacionamento gerencial.

Ao se abordar o tema liderança, muitas vertentes podem ser consideradas, relacionadas às habilidades que os líderes devem demonstrar, ou ao estilo que o líder pode adotar em função do foco dado às suas atividades, mais nos processos ou mais nas pessoas envolvidas. Também pode ser dada ênfase ao papel do liderado, ao que se espera dele e a como ele se posiciona em relação a isso. Todas essas possibilidades vão atuar dentro de um ambiente, ou situação, influenciando na maneira de a liderança ser exercida.

É importante conhecer o ambiente, que o líder possa conhecer as pessoas com quem trabalha, identificando as principais competências de cada um

Quadro 2. Competências de liderança.

\begin{tabular}{|c|c|}
\hline Grupo & Competência \\
\hline \multirow{4}{*}{$\begin{array}{c}\text { Competências emocionais } \\
\text { (EQ) }\end{array}$} & Motivação \\
\cline { 2 - 2 } & Conscienciosidade \\
\cline { 2 - 2 } & Sensibilidade \\
\cline { 2 - 2 } & Influência \\
\cline { 2 - 2 } & Rutoconsciência \\
\cline { 2 - 2 } $\begin{array}{c}\text { Competênciência emocional } \\
\text { (MQ) }\end{array}$ & Intuitividade \\
\hline \multirow{4}{*}{\begin{tabular}{c} 
Coestão de recursos \\
\cline { 2 - 2 } $\begin{array}{c}\text { Competências intelectuais } \\
(1 Q)\end{array}$
\end{tabular}} & Comunicação engajadora \\
\cline { 2 - 2 } & Desenvolver \\
\cline { 2 - 2 } & Capacitando \\
\cline { 2 - 2 } & Conspectiva estratégica \\
\cline { 2 - 2 } & Visão e imaginação \\
\cline { 2 - 2 } & Análise crítica e julgamento \\
\hline
\end{tabular}

Fonte: adaptado de Dulewicz e Higgs (2003). dos participantes das equipes. Porém, o exercício da liderança exige, também, uma constante busca de autoconhecimento. A missão da atuação do líder para obter sucesso é criar um ambiente no qual as pessoas possam demonstrar suas potencialidades.

A liderança em projetos vem sendo bastante pesquisada nos últimos anos, principalmente quanto às características presentes no gerente ou líder, mais adequadas em termos de resultados alcançados. Alguns trabalhos têm como foco central de estudo as características mais voltadas ao trabalho (TOOR; OFORI, 2008; DAVIES, 2002; BASS, 2008) ou ao contexto de relacionamento que o líder deve desenvolver com os liderados (KOLLTVEIT; KARLSEN; GRONHAUG, 2007; AVOLIO; GARDNER, 2005; KANGIS; KELLEY, 2000), alguns desses trabalhos considerando o ambiente situacional (KELLEY; LOONG, 2003; ESLAMI; KRALJEVIC; TUNBJER, 2005; MAKILOUKO, 2004; MULLER; TURNER, 2007) em termos de característica do projeto, suas atividades, o que influencia no comportamento dos liderados.

Dada a importância relacionada ao gerenciamento de projetos, é relevante entender qual o papel do gerente de projetos. É importante entender que eles são os integradores de objetivos funcionais, que precisam ser capazes de entender tudo das várias funções e de seu interrelacionamento. Aborda-se cada vez a liderança relacionada ao gerente de projetos.

Para Muller e Turner (2005), é surpreendente observar que a literatura sobre fatores de êxito em projetos normalmente não menciona a competência do gerente de projetos ou seu estilo de liderança como um fator de sucesso. 0 que está em contraste direto com a literatura geral de gerência, que vê a liderança adequada como um fator de sucesso crucial na gestão das organizações, levando a um melhor desempenho.

Considerando ainda que a área de projetos define seu quadro específico para a liderança, uma vez que, segundo Makilouko (2004), geralmente há uma quantidade limitada de tempo, dinheiro e outros recursos, os projetos também possuem algumas restrições. Em vez de uma organização estática, os projetos seguem os ciclos de vida rápidos, onde os papéis organizacionais mudam. Devido a isso, o líder tem que mudar seu papel, de técnico para gestor, líder e, finalmente, no final do projeto, voltar a ser um técnico especializado.

As típicas "folgas" e rápidas mudanças na estrutura de uma equipe de projeto contribuem para a liderança do projeto ser desafiadora. Assim, líderes de projeto podem ter estilos de liderança orientados para o trabalho ou para as relações durante as 
diferentes fases do projeto, para garantir a ordem na situação caótica, muitas vezes de tempo e pressão financeira, e de tarefas simultâneas. Enfatiza-se a necessidade de flexibilidade no ambiente de projeto em rápida mudança. Sendo assim, dentre as abordagens de liderança, uma que pode ser associada a projetos é a liderança situacional de Hersey e Blanchard (2007). Segundo eles, a liderança situacional é um instrumento que serve para ajudar as pessoas a compartilhar expectativas no seu ambiente, de modo que possam gradativamente aprender a supervisionar seu próprio comportamento e tornar as pessoas responsáveis e automotivadas.

\subsection{Liderança situacional de Hersey e Blanchard}

0 modelo de liderança situacional tem como base uma inter-relação entre a quantidade de orientação e direção (comportamento de tarefa) que o líder oferece, a quantidade de apoio socioemocional (comportamento de relacionamento) dado pelo líder e o nível de prontidão dos subordinados no desempenho de uma tarefa, função ou objetivo (maturidade) (McGINN; WILSON, 2006).

Hersey e Blanchard (2007) valorizaram os membros do grupo, declarando que a liderança devia ser exercida utilizando diferentes estilos de liderança, dependendo dos membros. 0 modelo também apresentou uma nova perspectiva ao enfocar os aspectos comportamentais no tocante a liderança. Os modelos de liderança não abordavam o comportamento em questão, concentrando-se na filosofia de gestão e atitudes/valores. Os dois autores argumentaram que comportamento é muito mais flexível do que atitudes e valores. Eles afirmam que o comportamento pode ser pensado de modo a obter um ótimo resultado, em uma particular situação, e que a atitude e valores, que são internos, são muito menos flexíveis.

0 estilo de liderança que um gerente deve utilizar para influenciar um indivíduo ou equipe vai depender do nível de maturidade destes últimos. Maturidade pode ser definida como a capacidade e a disposição das pessoas de assumir a responsabilidade de dirigir seu próprio comportamento. As relações entre nível de maturidade e respectivo estilo de liderança a ser adotado podem ser resumidas como no Quadro 3.

A liderança situacional tem orientado os gerentes na adoção de estilos mais compatíveis com as decisões para efeito de influência. É uma tentativa para adaptar um determinado estilo de liderança específico às circunstâncias externas. A ideia geral é que um tipo de liderança será eficaz em uma situação, mas um tipo diferente de liderança pode ser mais eficaz em outra. Historicamente, teorias de liderança situacional são demasiadas abstratas em termos de aplicações a situações específicas. No entanto, o conceito mantém considerável apelo intuitivo (SIMS JUNIOR; FARAJ; YUN, 2008).

Em função disto, abordar liderança de gerentes de projetos tendo como base o modelo de Hersey e Blanchard é importante, em razão deste não focar apenas um tipo de comportamento, considerando que os comportamentos dos liderados varia, o que requer mudanças também por parte do líder. Além disso, é uma abordagem que, em termos de entendimento e aplicação, é bastante conhecida, e o processo de atribuição de estilos é mais objetivo em função da maturidade envolvida.

Observa-se na prática um foco tradicional em alguns projetos, relacionado a execução das atividades, etapas do projeto, em que a orientação para tarefa pode ser ainda bastante explorada. Um exemplo de tal situação é no setor da construção. Muitos pesquisadores na indústria da construção têm explorado estilos de liderança sustentáveis para profissionais da área. Eles observaram que o modelo de liderança situacional tem sido amplamente utilizado, e em alguns estudos os gestores de projetos que ofereceram maior orientação para a tarefa no trato com seus funcionários tiveram melhor desempenho (TOOR; OFORI, 2008).

Quadro 3. Níveis de maturidade dos subordinados e estilos de liderança requeridos.

\begin{tabular}{|l|l|}
\hline \multicolumn{1}{|c|}{ Nivel de maturidade } & \multicolumn{1}{c|}{ Estilo de liderança } \\
\hline $\begin{array}{l}\text { M1 - Maturidade baixa: pessoas sem } \\
\text { capacidade e sem disposição. }\end{array}$ & $\begin{array}{l}\text { E1 - Determinar: para pessoas que não tem capacidade nem vontade de assumir a } \\
\text { responsabilidade de fazer os padrões. }\end{array}$ \\
\hline $\begin{array}{l}\text { M2 - Maturidade entre baixa e moderada: } \\
\text { pessoas sem capacidade, mas com disposição. }\end{array}$ & $\begin{array}{l}\text { E2 - Persuadir: é o estilo a ser adotado para pessoas que sentem disposição, mas não } \\
\text { tem capacidade. }\end{array}$ \\
\hline $\begin{array}{l}\text { M3 - Maturidade entre moderada e alta: } \\
\text { pessoas com capacidade, mas sem disposição. }\end{array}$ & $\begin{array}{l}\text { E3 - Compartilhar: para maturidade entre alta e moderada: As pessoas neste nível de } \\
\text { maturidade têm capacidade, mas não estão dispostas a elaborar os padrões. }\end{array}$ \\
\hline $\begin{array}{l}\text { M4 - Maturidade alta: pessoas com } \\
\text { capacidade e com disposição. }\end{array}$ & $\begin{array}{l}\text { E4 - Delegar: as pessoas neste nível de maturidade têm capacidade e disposição para a } \\
\text { elaboração de padrões. }\end{array}$ \\
\hline
\end{tabular}

Fonte: baseado em Hersey e Blanchard (2007). 
A liderança situacional de Hersey e Blanchard (2007) continua muito popular entre profissionais, apesar das críticas acadêmicas, relacionadas à falta de debate teórico (AVERY; RYAN, 2001). Segundo estes autores, em uma pesquisa realizada por eles na Austrália, os gerentes recorreram a tal modelo pela sua simplicidade intuitiva, facilidade de utilização e relevância percebida para cargos diretivos. Os profissionais não relataram dificuldades na avaliação dos níveis de maturidade dos seguidores.

Em função da popularidade do modelo entre gestores, ele foi aplicado como meio para o estudo de liderança na indústria de transformação e de serviços em numerosos cenários (GROVER; WALKER, 2003), e paises de todo o mundo (AVERY; RYAN, 2001; GALVÃO; SILVA, 2007; SILVERTHORNE; WANG, 2001). Os resultados da investigação sobre sua validade como teoria são mistos, com o modelo recebendo apoio parcial para a sua validade como uma teoria explicativa da liderança (FERNANDEZ; VECCHIO, 1997).

Contudo, o modelo dos autores é criticado por alguns pesquisadores e acadêmicos por ter poucas bases teóricas e pouco suporte de pesquisa. Graeff (1997) apontou que o modelo, apesar de popular, apresenta inconsistências na relação entre comportamento de tarefa e maturidade. Inconsistência essa considerada exacerbada pela ambiguidade associada ao conceito de maturidade de tarefa usado no modelo normativo. Graeff também argumenta que a atenção dada à liderança situacional, segundo Hersey e Blanchard (2007), ainda é limitada, apesar de alguns estudos já fornecerem suporte ao modelo, se não completamente ao menos com relação a alguns níveis.

Apesar disto, muitos gerentes consideram o modelo uma ferramenta de gerenciamento válida, porque provém uma estrutura para gerenciar pessoas, é relevante, útil, intuitivo e um jogo de senso comum. Sua popularidade deriva da simplicidade do modelo, de fácil uso e importância para o papel do gerente.

\subsection{A problemática da seleção de estilos de liderança}

A maioria dos projetos possui tempo limitado para concluir tarefas, o que pode impedir um gerente de construir relacionamentos e obter apoio e lealdade da equipe, especialmente se os membros da equipe devem regressar ao grupo original após a conclusão do projeto (KANGIS; KELLEY, 2000). Uma vez que cada projeto é uma situação nova, o gerente de projeto precisa adaptar seus estilos de liderança à situação única do projeto.
Pesquisas referentes à aplicação da abordagem situacional são realizadas há algum tempo, com a contribuição de alguns autores. Dentre estes podem-se destacar o trabalho de Silverthorne e Wang (2001), em cujo estudo, com 79 gerentes e 234 subordinados de 20 empresas de Taiwan, concluíram que, quanto maior a adaptabilidade do líder, maior a produtividade observada, medida em termos de unidades produzidas e índice de rejeição. Deste modo, líderes com maior facilidade para adaptar seu estilo de liderança apresentam um impacto positivo sobre a qualidade e produtividade em suas organizações.

Chen e Silverthorne (2005) realizaram uma pesquisa com 126 gerentes de indústrias e prestadoras de serviço nos Estados Unidos a respeito da teoria da liderança situacional. Os autores concluíram que líderes com maior adaptabilidade apresentavam subordinados com maior disposição para realizar as tarefas, menor intenção de mudar de emprego, maior satisfação e menor estresse no trabalho.

Eslami, Kraljevic e Tunbjer (2005) desenvolveram um trabalho na área de gerenciamento de projetos demonstrando que o modelo de liderança situacional foi capaz de predizer o comportamento de liderança adequado a adotar, não tendo sido, porém, aprovado em todos os projetos.

Estes e outros estudos mostram que não há acordo sobre o estilo de liderança que melhor se adequa a profissionais e gerentes de projeto, em função de nenhum estilo de liderança poder ser considerado o melhor em todas as circunstâncias. 0 contexto é um fator vital para o sucesso e a eficácia de qualquer estilo de liderança.

Um aspecto importante se refere a como identificar da maneira mais acertada possível um comportamento ou estilo de liderança que deveria ser adotado por um gerente de projetos. $\mathrm{Ou}$, indo talvez mais além, de acordo com o modelo de Hersey e Blanchard (2007), onde conta-se não só com o líder, mas com a tarefa e liderados, e é para estes últimos em especial que o comportamento do líder será orientado. Como se poderia averiguar, de maneira mais precisa e confiável, o nível de maturidade dos liderados?

Segundo os autores, a experiência afeta a capacidade, enquanto a motivação da realização afeta a disposição. Assim, o conceito maturidade incluirá duas dimensões: maturidade de trabalho e maturidade psicológica. A maturidade de trabalho seria a capacidade de fazer algo, o conhecimento e a capacidade técnica. A maturidade psicológica refere-se a disposição ou motivação para fazer algo. 
A maneira de identificar a maturidade dos liderados seria pela aplicação de um formulário denominado Avaliação do Nível de Maturidade de Trabalho e Avaliação do Nível de Maturidade Psicológica, no qual cada liderado é avaliado na execução da tarefa, pontuando de 1 a 8 . 0 formulário mede as cinco escalas relacionadas à capacidade (maturidade de trabalho) e à disposição (maturidade psicológica) do liderado em relação a uma tarefa específica. A média aritmética simples das notas atribuídas determinaria o nível de maturidade do liderado, em que os extremos $M_{4}$ e $\mathrm{M}_{1}$ representam o liderado maduro e imaturo, respectivamente. Esta relação pode ser visualizada na Figura 1.

A ideia seria, para subordinados de baixa maturidade, quanto maior a orientação para tarefas, maior a satisfação no trabalho. Para subordinados de alta maturidade, essa relação também seria válida, porém com intensidade bem menor, pois a satisfação no trabalho é alta mesmo com baixa orientação para tarefa.

Contudo, esta maneira de definir nível de maturidade é muito simplista, não refletindo as características das tarefas e de pessoas que talvez seja importante considerar na avaliação. É preciso considerar a necessidade de um instrumento que seja mais "confiável" ou que permita ao gerente trabalhar melhor aspectos que ele considere importante o liderado apresentar, e em qual grau, e que com o passar do tempo podem mudar. Tal ferramenta precisa ser capaz de absorver tais mudanças de maneira confiável.
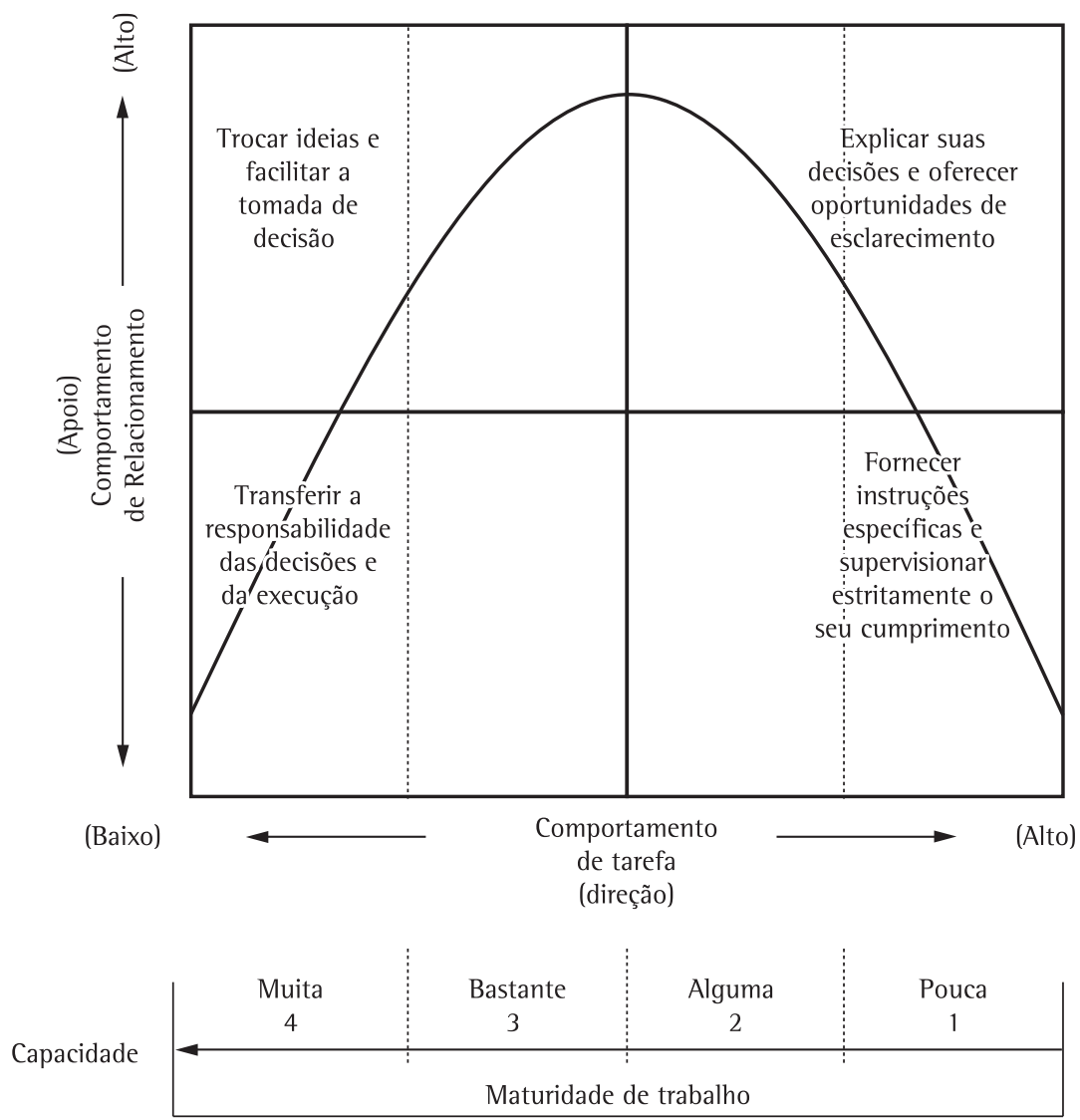

Esta pessoa é CAPAZ (tem o conhecimento necessário)

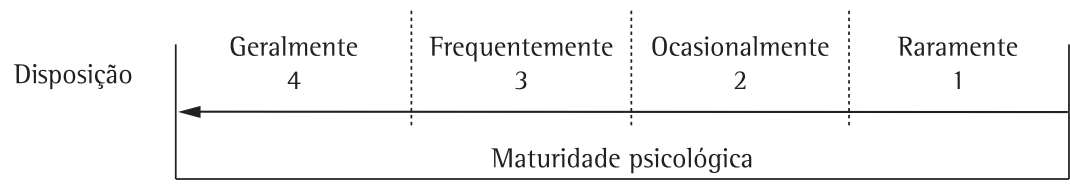

Esta pessoa está DISPOSTA (possui a confiança em si mesma)

\section{Maturidade dos subordinados}

Figura 1. Definição da maturidade e dos estilos de liderança. Fonte: adaptado de Hersey e Blanchard (2007). 
Para demonstrar a complexidade associada à avaliação do nível de maturidade dos liderados, uma pesquisa foi realizada junto a um grupo de dez funcionários de uma empresa de tecnologia da informação (Tl). 0 objetivo foi demonstrar que, para definir os níveis de maturidade, é importante avaliar aspectos que muitas vezes são responsáveis pela classificação de um funcionário em um nível $M_{1}$ e não em $M_{3}$. Ou seja, deve-se abandonar a ideia simplista de avaliação do comportamento desses liderados e absorver no processo as complexidades associadas às tarefas e pessoas. Até para o gerente identificar se será válido investir em algumas dessas pessoas em um futuro próximo.

\section{Pesquisa em uma empresa de projetos de $\mathrm{Tl}$}

A empresa caso existe há seis anos, sua sede é na cidade de Recife (PE) e ela atua nos segmentos de tecnologia da informação e design gráfico. Para desempenhar suas atividades, conta com profissionais que atuam em quatro núcleos:

- Núcleo de Desenvolvimento: responsável pela definição e análise de requisitos, projetos, implementação e implantação de sistemas e websites, além de treinamento.

- Núcleo de Criação: onde a geração e a concretização de ideias são efetuadas.

- Núcleo de Suporte e Manutenção: a ele cabe a montagem e manutenção de infraestrutura computacional ajustada à da empresa cliente.

- Núcleo de Domínios e Hospedagem: responsável por gerenciar os domínios junto aos órgãos de registro, além de prover infraestrutura adequada à publicação de websites na internet.

Em sua carteira de clientes constam diversas empresas, dos mais variados segmentos, como comunicação, construção civil, consultoria, contabilidade e jurídico, do governo, da indústria e comércio etc. Mediante breve descrição das atividades desenvolvidas pela empresa caso, fica clara sua necessidade em contar com colaboradores que possam realizar uma variedade de tarefas desejadas pelos clientes.

Os questionários para avaliação dos liderados foram entregues pessoalmente ao gerente da empresa, que os preencheu no período de uma tarde do mês de julho de 2009. 0 gerente da empresa avaliou a maturidade de seus 10 liderados, considerando as escalas para capacidade e disposição constantes no formulário original de Hersey e Blanchard, sendo a pontuação baseada nas escalas de resposta tipo likert de sete pontos, por permitir que os respondentes não apenas respondam se concordam ou não com as afirmações, mas também informem seu grau de concordância. No questionário fechado entregue ao gerente, foram feitas dez afirmações acerca do comportamento de cada liderado, cinco afirmações para cada escala do modelo dos autores.

Assim, cada pergunta foi classificada em uma escala de sete pontos do tipo concorda - discorda, aprova - reprova etc. À atitude mais favorável em relação ao item é atribuída uma nota de uma escala de sete posições. 0 pesquisador seleciona os itens que foram melhor discriminados (notas altas e notas baixas), o que resulta em itens nitidamente favoráveis ou desfavoráveis ao conceito para a maioria dos indivíduos. A partir de suas medidas de favorabilidade, os avaliados são ordenados (HAIR JUNIOR et al., 2006).

Para maturidade no trabalho, os critérios avaliados foram: experiência do liderado, educação/ experiência, solução de problemas, capacidade de assumir responsabilidades, conhecimento da tarefa. Para maturidade psicológica, os critérios considerados foram: desejo de assumir responsabilidades, comprometimento, persistência, atitude no trabalho, iniciativa em tarefas novas.

Quanto à experiência dos liderados na tarefa que realizam atualmente, e em tarefas similares já realizadas em outros projetos, o gerente considera seus liderados experientes em uma concordância de 100\%. Quanto à participação anual do liderado em programas de qualificação, cursos e treinamentos, houve concordância por parte do gerente em 70\% dos casos. Os liderados também foram avaliados de maneira favorável quanto à solução de problemas e capacidade de assumir responsabilidades em mais de 60\% dos casos. Quanto ao interesse do liderado em conhecer com mais detalhes a tarefa que irá realizar através de pesquisas, treinamentos, o gerente concordou em 50\% dos casos, não concordando sobre alguns deles apresentarem tal comportamento em $20 \%$ dos casos.

Assim, poderia se considerar, quanto à maturidade em capacidade, que os liderados apresentam um nível de maturidade tendendo ao $\mathrm{M}_{3}$ ou $\mathrm{M}_{4}$, ou seja, teria se liderados maduros para tarefa em questão. Na Figura 2 veem-se os resultados, com as escalas de concordância detalhadas.

$\mathrm{Na}$ avaliação da maturidade psicológica, quanto ao desejo dos liderados em conhecer as tarefas do projeto no qual está envolvido, seus detalhes, habilidades necessárias, o gerente avaliou positivamente em 50\% dos casos, havendo uma discordância de 40\% quanto à afirmação. No critério comprometimento dos liderados com o fator tempo para entrega, além da qualidade e custo para o sucesso, houve uma concordância do 
gerente em 80\%. No critério persistência, onde o gerente avaliou o grau em que o liderado demonstra interesse e segurança para analisar a situação e propor ideias de solução, houve concordância em mais de $60 \%$ do número de liderados avaliados. A atitude no trabalho desses liderados quanto a expor para outras pessoas suas principais dificuldades e qualidades na realização da tarefa foi avaliada de maneira favorável pelo gerente em mais de 70\% dos casos. Resultado parecido foi obtido no critério iniciativa em participar de projetos bem variados.

Avaliando esses resultados, os liderados poderiam ser considerados maduros em níveis tendendo ao $M_{3}$ ou $M_{4}$ por apresentarem, segundo o gerente, pontuações favoráveis na escala. A Figura 3 mostra os resultados.

Analisando-se os resultados obtidos com esta pesquisa verifica-se a necessidade de um instrumento mais elaborado para avaliar os liderados de uma empresa. 0 problema de avaliações simples como a apresentada para definir o nível de maturidade do liderado e assim definir o estilo de liderança a ser adotado pelo gerente é que tal instrumento avalia o todo, não discriminando como cada funcionário está em relação a cada critério e como eles podem ser comparados entre si. Como saber o mais acertadamente possível se o liderado é $\mathrm{M}_{3}$ ou $\mathrm{M}_{4}$ e quais critérios são determinantes nessa definição?

Observa-se que às vezes os liderados de qualquer empresa têm desempenhos, comportamentos parecidos, havendo, contudo, diferenças em características que muitas vezes podem ser decisivas na atribuição de tarefas pelo líder, como facilidade de comunicação, engajamento, rapidez para solucionar problemas, enfim, características algumas vezes pessoais e importantes. Para se obter uma ordenação de níveis é importante a adoção de um instrumento que permita uma comparação entre os liderados.

A importância de realizar tal avaliação consiste em entendê-la como parte de um processo de gestão de pessoas, ponto de partida para discutir a interação social entre líder e liderado e a noção de modificar o comportamento do líder em função dos atributos dos liderados.

\subsection{Proposta de um instrumento de avaliação da maturidade}

Considerando o exposto, apresenta-se a possibilidade de verificar a aplicabilidade de um instrumento genérico que permita ao gerente considerar critérios que sejam importantes nos liderados, além das habilidades necessárias à realização das tarefas, para saber como estes

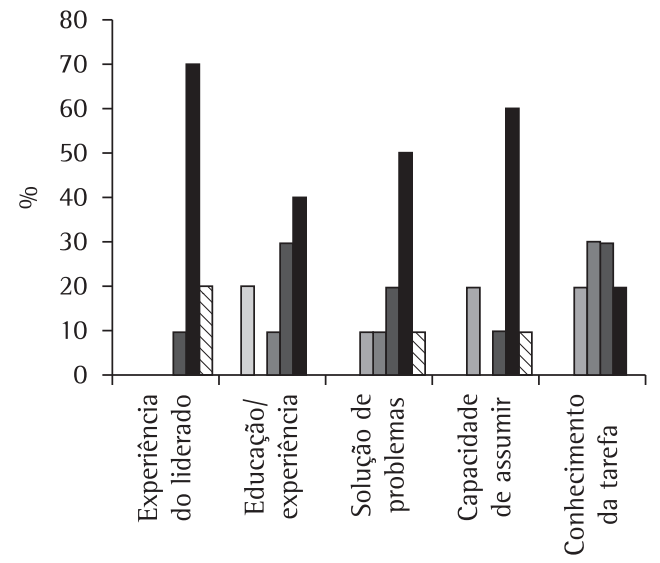
$\square$ Discordo totalmente $\square$ Discordo em grande parte
$\square$ Discordo em parte
$\square$ Indiferente
$\square$ Concordo em parte
$\checkmark$ Concordo totalmente

Figura 2. Maturidade no trabalho. Fonte: as autoras (2009).

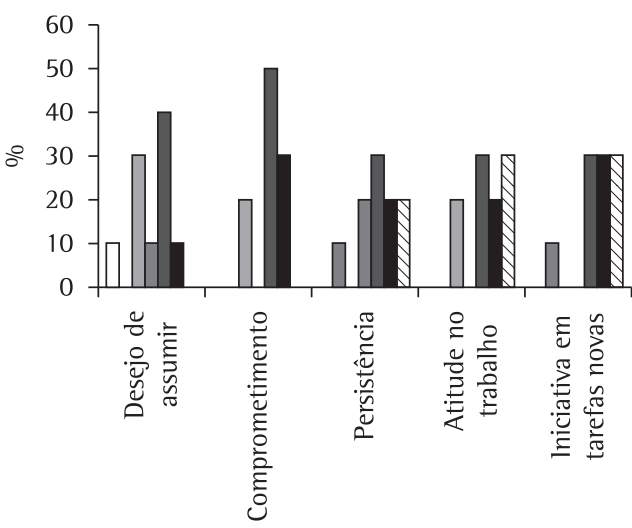

$$
\begin{array}{ll}
\square \text { Discordo totalmente } & \square \text { Discordo em grande parte } \\
\square \text { Discordo em parte } & \square \text { lndiferente } \\
\square \text { Concordo em parte } & \square \text { Concordo em grande parte } \\
\square \text { Concordo totalmente } &
\end{array}
$$

Figura 3. Maturidade psicológica. Fonte: as autoras (2009).

liderados se encontram em relação a tais critérios, para então o líder, em seu papel de influenciador, ajudar no crescimento e amadurecimento, nas tarefas e no ambiente de trabalho. Muitos trabalhos relacionados à liderança situacional buscam verificar sua eficiência e o sucesso dos líderes em adaptação, identificando inclusive alguns estilos que às vezes são mais eficientes que outros em função do ambiente. Em projetos não é diferente, em termos de qual abordagem ou estilo pode assegurar uma maior chance de sucesso (SILVA, 2008). 
Segundo o modelo de Hersey e Blanchard (2007) quando um liderado apresenta certo nível de maturidade, o líder deve utilizar um estilo de liderança correspondente já determinado pela própria teoria. Por exemplo, caso um funcionário ao ser avaliado apresente uma maturidade nível $\mathrm{M}_{2}$, o estilo a ser adotado será $\mathrm{E}_{2}$.

Quando se considera a pesquisa na empresa de Tl, vê-se a necessidade de um método mais eficiente na identificação, individualmente, das maturidades, para a partir daí atribuir um estilo adequado, ou o mais adequado possível, que inclusive permita a comparação das diferentes visões entre líder e liderados. Nos dados apresentados na pesquisa viu-se como o líder avalia a maturidade do grupo de liderados sem fazer uma identificação individual e comparativa entre eles. Neste ponto, este artigo visa exatamente considerar estas individualidades, compará-las e ajudar o gerente a adotar um estilo coerente para com cada liderado e não apenas a identificar uma maturidade dominante e adotar o mesmo estilo para todos.

Assim, um instrumento de três etapas principais pode ser proposto. A primeira consiste na definição das características do projeto, tipo e estrutura organizacional. A etapa seguinte consiste na avaliação dos liderados de acordo com os critérios que forem estabelecidos. A terceira etapa é, a partir da ordenação desses liderados, realizar a atribuição de estilos de liderança mais apropriados a cada um.

Todo esse processo é interativo, pois em qualquer fase pode haver a necessidade de voltar para a anterior, visando melhorar e facilitar o processo de decisão. 0 fluxograma apresentado na Figura 4 mostra a sequência das atividades desenvolvidas. Em seguida estas fases são detalhadas.

A ideia básica é que a partir destas três etapas o gerente possa conhecer seu ambiente e descobrir o caminho a seguir para lidar com seus liderados. Estas fases na verdade funcionariam como um passo inicial para o desenvolvimento do processo de liderança eficaz.

\subsubsection{Características do projeto}

Em um primeiro momento é necessário que sejam definidas as características principais do projeto. A definição dessas características servirá como inputs para que o gerente possa conhecer o ambiente onde irá trabalhar, além de esboçar, mesmo que de maneira ainda geral, um perfil das pessoas que ele precisa para desenvolver o projeto.

É necessário conhecer o tipo de projeto em questão, se ele se refere a um projeto de construção, projeto de tecnologia da informação, projeto empresarial, para que sejam definidas

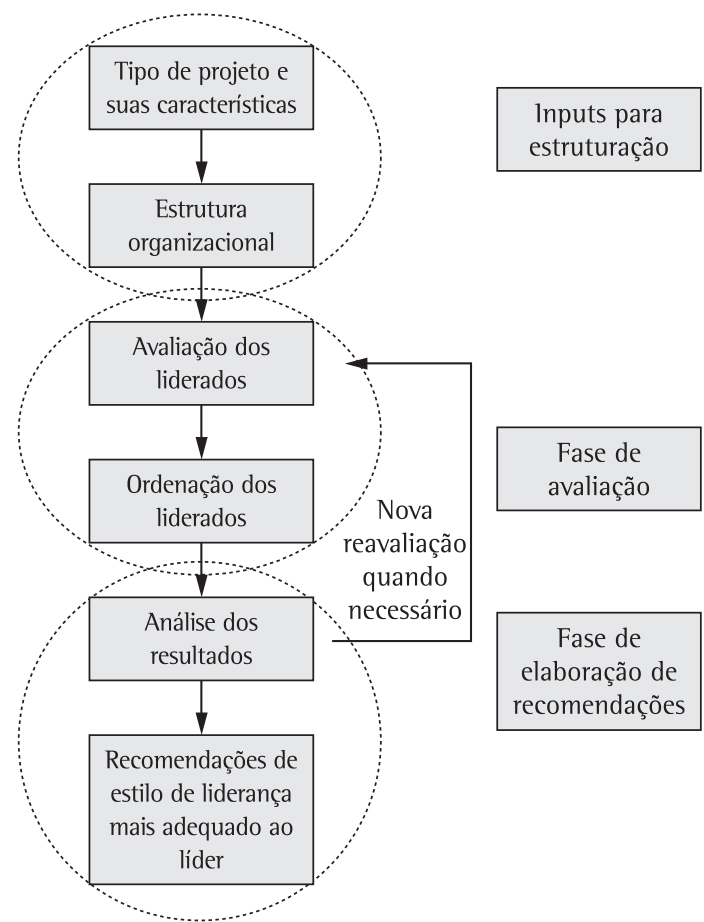

Figura 4. Fases para avaliação da maturidade e seleção de estilo. Fonte: as autoras (2009).

as tarefas a serem realizadas e a variedade de habilidades requeridas dos liderados. Em geral se espera que tarefas mais complexas tenham um acompanhamento mais acurado por parte dos gerentes (orientação para tarefa), em especial quando os liderados não apresentam muita experiência naquela tarefa. Para tarefas com nível baixo de complexidade, a ênfase poderia ser deslocada para uma orientação ao relacionamento.

Quando se fala em projetos voltados para área de tecnologia da informação, por exemplo, foco da pesquisa realizada, estes se diferenciam de maneira significativa dos outros tipos de projetos, uma vez que são caracterizados por sua alta complexidade e por altas chances de falhas.

Segundo Rodriguez-Repiso, Setchi e Salmeron (2007), as principais características dos projetos de Tl são: exigências abstratas, percepção excessiva de flexibilidade, incerteza, tendência à falha do software e objetivo de mudar as características dos processos existentes no negócio. As consequências de tais aspectos podem ser, dentre outras: expectativas irrealistas, pedidos frequentes de mudanças, entregas fora do prazo, gastos acima do orçamento, dificuldade na definição de especificações, problemas na implementação do sistema específico e detecção tardia de problemas. 
Algumas dificuldades tipicamente encontradas na prática do gerenciamento de projetos de $\mathrm{Tl}$ são: projetos geralmente mal definidos e, em alguns casos, poucas lições podem ser aprendidas com experiências passadas; pressões do mercado exigem entregar no menor tempo possível, mesmo que o resultado seja uma menor qualidade do produto.

A construção civil por sua vez, apresenta um conjunto particular de características, de natureza do processo produtivo e do próprio mercado em que a aplicação dos conceitos e procedimentos trazidos pelas modernas teorias de gestão encontra uma série de dificuldades e deve sofrer adaptações para permitir sua implementação.

Ou seja, a importância de conhecer o tipo de projeto reside em identificar algumas dificuldades específicas que por vezes poderão influenciar na análise. Também para que o gerente possa entender a importância de alguns critérios a serem avaliados, e quando necessário estabelecer pesos (ponderação) diferentes para eles.

Também é importante conhecer a estrutura organizacional onde o projeto será desenvolvido, a maneira como as empresas se organizam, agrupam recursos humanos e materias para atingir as metas, uma vez que os projetos geralmente são uma parte da organização. Além disso, devem-se considerar informações relacionadas a tempo para término do projeto, qualificações necessárias, qualidade esperada enfim, informações que forneçam uma ideia clara de seu ambiente e do que será esperado dos liderados para o gerente de projetos.

\subsubsection{Avaliação dos liderados}

Nesta etapa é realizada uma avaliação dos liderados para definição de seus níveis de maturidade. Um dos problemas verificados na relação direta entre nível de maturidade dos liderados e estilo de liderança a ser adotado pelo líder, de acordo com a abordagem de Hersey e Blanchard (2007), se refere à possibilidade de haver uma compensação entre as duas escalas medidas (capacidade e disposição), o que pode levar à adoção de um estilo que não é o mais adequado. Além disto, quando se aborda o comportamento de pessoas, muitas questões subjetivas (confiança, motivação, segurança, frustração etc.) às vezes não são avaliadas como deveriam, o que pode gerar perda de informações cruciais.

É importante considerar que, segundo os autores, um grupo pode apresentar certo nível de maturidade, contudo um indivíduo desse grupo pode apresentar nível de maturidade diferente. 0 ideal seria que para cada um o líder pudesse adotar um estilo de liderança adequado. Na verdade, é isto o que os autores propõem.
Mesmo para aqueles liderados que se encontram em uma mesma classificação $M$ de nível de maturidade pode haver diferenças. Isto é, dois liderados podem estar em um nível de maturidade $\mathrm{M}_{1}$, por exemplo, requerendo bastante foco na tarefa, mais orientação, porém, um deles pode apresentar um nivel de imaturidade maior do que o do colega, requerendo mais atenção por parte do líder. Ou seja, é importante saber o nível de maturidade de cada liderado, para que o líder consiga de fato adotar o estilo certo, focando em tarefas ou relacionamento, mas em função dessas diferenças reais de maturidade.

Para promover o crescimento do indivíduo para o nível de maturidade mais alto $\left(\mathrm{M}_{4}\right)$ não basta apenas que o líder determine o nível de maturidade de seu liderado e aplique o estilo de liderança mais adequado. Este é um requisito necessário, mas não suficiente. 0 líder precisa conduzir um processo de amadurecimento do liderado, que deve ser lento e gradual, sempre no sentido de $M_{1}$ para $M_{4}$.

Russo, Ruiz e Cunha (2005) ressaltam que as pessoas estão sujeitas, por fatores internos e externos à organização, a regredir em seu nível de maturidade. Neste caso, o líder deve reavaliar a maturidade do subordinado, voltando ao estilo de liderança adequado, a fim de lhe fornecer apoio socioemocional e direção apropriados. Ele deve estar constantemente atento às situações de regressão, pois o processo de retorno a um estágio já alcançado será mais dispendioso quanto mais tempo decorrer entre a regressão e a efetiva intervenção de apoio.

Sendo assim, é necessária a identificação dos níveis de maturidade entre os liderados, para uma posterior ordenação desses liderados dentro do próprio grupo.

Para avaliação, pode-se utilizar a adaptação da ferramenta criada por Hersey e Blanchard sugerida, que mede em escalas de maturidade no trabalho e maturidade psicológica usando o questionário com a escala Likert de sete pontos para avaliar individualmente cada liderando em relação aos critérios e ordená-los, buscando eliminar efeitos de compensação. A concordância estaria associada aos níveis mais altos de maturidade, em uma análise bem simples. Esta ordenação é um ponto novo e crucial nesse processo, pois considera exatamente as diferenças entre os liderados, mesmo quando eles estão em um mesmo nível de maturidade.

\subsubsection{Recomendações sobre estilo de liderança mais apropriado}

A última etapa consiste em, a partir da identificação dos níveis de maturidade dos liderados 
e sua ordenação, realizar a atribuição de estilos de liderança mais apropriada a cada um. Tal atribuição seguiria o que é proposto na abordagem situacional de Hersey e Blanchard (2007) quanto aos estilos adequados mais eficazes de serem adotados.

\section{Conclusão}

$\mathrm{Na}$ busca de entender melhor como pode ser estabelecida de forma coerente a relação entre projetos, mais precisamente gerentes de projetos, e liderança, algumas das teorias de liderança vêm sendo estudadas nesse ambiente específico, que possui características únicas relacionadas a prazo, custo, qualidade e objetivo a ser alcançado.

A liderança situacional, mais especificamente 0 modelo dos autores Hersey e Blanchard, permanece muito popular entre os profissionais (AVERY; RYAN, 2001). Muitos gerentes aplicam o modelo por considerarem fácil de utilizar, devido à sua simplicidade intuitiva, e em função dessa popularidade e aplicabilidade, foi escolhido neste trabalho.

Mas se observam ainda lacunas sobre ferramentas mais apuradas que auxiliem os gerentes a avaliar liderados para posteriormente definir um estilo de liderança. Ou seja, um instrumento que considere aspectos subjetivos associados à liderança, que são essenciais.

Tal necessidade ficou mais evidente neste artigo a partir dos resultados da pesquisa realizada na empresa de $\mathrm{Tl}$, onde foi difícil identificar um nível de maturidade para cada funcionário avaliado pelo gerente. A partir desse fato, no artigo foi proposto um instrumento que permita tal identificação.

Neste trabalho acenou-se com a ideia de utilizar um método que permita ordenar os liderados segundo o nível de maturidade, inclusive em termos de liderados em um mesmo nível, definido por Hersey e Blanchard (2007), para apresentar no grupo não só os diferentes níveis de maturidade mas as diferenças entre liderados em um mesmo nível, numa classificação do liderado mais imaturo até o que se encontra em nível de maturidade alta. A partir de tal ordenação, a etapa seguinte seria realizar as recomendações de liderança apropriada aos liderados.

0 processo de atribuição de estilo de liderança não é fácil, por tratar de aspectos comportamentais das pessoas, onde o líder às vezes pode entender que os liderados estão em um determinado nível de maturidade quando na verdade estão em outro. Quando se considera o ambiente de projetos, a identificação rápida de um estilo adequado, bem como flexibilização desse estilo, muitas vezes em função de uma nova etapa ou tarefa, se faz extremamente necessária, exigindo do gerente de projetos decisões rápidas.
Tal ideia carece ainda de aplicação prática, mas é vista como oportunidade de contribuir para este modelo de liderança situacional. Hughes, Ginnett e Curphy (2002) comentam que, apesar da investigação escassa sobre o modelo de Hersey e Blanchard, este é uma forma útil para levar líderes a refletir como uma liderança eficaz pode depender, em parte, de ser flexível com diferentes liderados, não agindo da mesma maneira com todos eles.

0 que se busca, na verdade, é, partindo da avaliação do comportamento dos liderados, tornar o processo de atribuição de estilos de liderança mais eficiente.

\section{Referências}

AVERY, G. C.; RYAN, J. Applying situational leadership preferences in Australia: congruity, flexibility and effectiveness. Leadership \& Organization Development Journal, v. 22, n. 1, p. 11-21, 2001. http://dx.doi. org/10.1108/01437730110380183

AVOL10, B. J.; GARDNER, W. L. Authentic leadership development: getting to the root of positive forms of leadership. The Leadership Quarterly, v. 16, p. 315-338, 2005. http://dx.doi.org/10.1016/j.leaqua.2005.03.001

BASS, B. M. Bass and stodghill handbook of leadership: theory, research and applications. $4^{\text {th }}$ ed. New York: Free Press, 2008.

BERGAMIN1, C. W. Liderança administração do sentido. São Paulo: Atlas, 1999.

CHEN, J. C.; SILVERTHORNE, C. Leadership effectiveness, leadership style and employee readiness. Leadership \& Organization Development Journal, v. 26, n. 4, p. 280-288, 2005. http://dx.doi.org/10.1108/01437730510600652

DAVIES, T. C. The "real" success factors on projects International Journal of Project Management, v. 20, n. 8, p. 185-190, 2002.

DULAIMI, M.; LANGFORD, D. A. Job behavior of construction project managers: determinants and assessment. Journal of Construction Engineering and Management, v. 125, n. 4, p. 56-64, 1999. http://dx.doi.org/10.1061/(ASCE)07339364(1999)125:4(256)

DULEWICZ, V.; HIGGS, M. Assessing leadership styles and organisational context. Journal of Managerial Psychology, v. 20, n. 2, p. 105-123, 2005. http://dx.doi. org/10.1108/02683940510579759

DULEWICZ, V.; HIGGS, M. J. Design of a new instrument to assess leadership dimensions and styles. UK: Henley Management College, 2003. (Henley Working Paper Series, $0311)$.

ESLAMI, A.; KRALJEVIC, M.; TUNBJER, M. Project management from a situational leadership perspective. Tese (Bachelor's Thesis in Management)-Internationella Handelshögskolan, Suécia, 2005.

FERNANDEZ, C.; VECCHIO, R. Situational leadership theory revisited: A test of an across-jobs perspective. Leadership Quarterly, v. 8, n. 6, p. 67-84, 1997. http://dx.doi. org/10.1016/S1048-9843(97)90031-X

GALVÃO, C. M.; SILVA, M. A. Use of the situational leadership in surgical center nursing. Revista da Escola de Enfermagem da USP, v. 41, n. 1, p. 104-12, 2007.

GOLEMAN, D.; BOYATZIS, R. E.; McKEE, A. The new leaders. Cambridge, MA: Harvard Business School Press, 2003. 
GRAEFF, C. L. Evolution of situational leadership theory: a critical review. Leadership Quartely, v. 8, n. 2, p. 153-170, 1997. http://dx.doi.org/10.1016/S1048-9843(97)90014-X

GROVER, R. A.; WALKER, H. F. Changing from production to quality: Application of the situational leadership transtheoretical change models. The Quality Management Journal, v. 10, p. 8-24, 2003.

HAIR JUNIOR, J. F. et al. Fundamentos de métodos de pesquisa em administração. São Paulo: Bookman, 2006.

HERSEY, P.; BLANCHARD, K. Management of organizational behavior. $5^{\text {th }}$ ed. Englewood Cliffs, NJ: Prentice-Hall, 2007.

HUGHES, R.; GINNETT, R.; CURPHY, G. Leadership: enhancing the lessons of experience. New York: McGraw-Hill lrwin, 2002. In: GROVER, R. A.; WALKER, H. F. Changing from production to quality: application of the situational leadership transtheoretical change models. The Quality Management Journal, v. 10, n. 3, p. 8-24, 2003.

KANGIS, P.; KELLEY, L. L. Project leadership in clinical research organizations. International Journal of Project Management, v. 18, n. 6, p. 393-401, 2000. http://dx.doi. org/10.1016/S0263-7863(00)00018-1

KEEGAN, A. E.; HARTOG, D. N. D. Transformational leadership in a project-based environment: a comparative study of the leadership styles of project managers and line managers. International Journal of Project Management, v. 22, n. 8, p. 609-617, 2004. http://dx.doi.org/10.1016/j. ijproman.2004.05.005

KELLEY, L. L.; LOONG, K. L. Turner's five-functions of projectbased management and situational leadership in IT services projects. International Journal of Project Management, v. 21, p. 583-591, 2003. http://dx.doi.org/10.1016/ S0263-7863(02)00100-X

KOLLTVEIT, B. J.; KARLSEN, J. T.; GRONHAU, G. K. Perspectives on project management. International Journal of Project Management, n. 25, p. 3-9, 2007. http://dx.doi. org/10.1016/j.ijproman.2005.12.002

KOUZES, J. M.; POSNER, B. Z. The leadership challenge. $4^{\text {th }}$ ed. Wiley-VCH Verlag GmbH, 2007.

LUTHANS, F. Organizational behavior. $10^{\text {th }}$ ed. McGraw-Hill, 2005.

MAKILOUKO, M. Coping with multicultural projects: the leadership styles of Finnish project managers. International Journal of Project Management, v. 22, p. 387-396, 2004. http://dx.doi.org/10.1016/j.jproman.2003.08.004

McGINN, C.; WILSON, B. C. An instrument for assessing group maturity levels - Based on hersey and blanchard's situational leadership theory. Organizational Training and Development University of Rhode lsland, 2006.

MONTANA, P. J.; CHARNOV, B. H. Administração. 3. ed. São Paulo: Saraiva, 2003

MULLER, R.; TURNER, J. R. Matching the project manager's leadership style to project type. International Journal of Project Management, v. 25, n. 1, p. 21-32, 2007. http://dx.doi.org/10.1016/j.jproman.2006.04.003

MULLER, R.; TURNER, J. R. The project manager's leadership style as a success factor on projects: a literature review. Project Management Journal, v. 36, n. 1, p. 49-61, 2005.

ROBBINS, S. Organisational behaviour. concepts, controversies and applications. $11^{\text {th }}$ ed. New Jersey: Prentice Hall, 2005.

RODRIGUEZ-REPISO, L.; SETCHI, R.; SALMERON, J. L. Modelling IT projects success: emerging methodologies reviewed. Technovation, v. 27, p. 582-594, 2007. http://dx.doi.org/10.1016/j.technovation.2006.12.006

RUSSO, R. F. S. M.; RUIZ, J. M.; CUNHA, R. P. Liderança e influência nas fases da gestão de projetos. Revista Produção, v. 15, n. 3, p. 362-375, 2005.

SILVA, U. B. Transferência de tecnologia para desenvolvimento de equipe através da teoria da liderança situacional e do feedback $360^{\circ}$ : caso de uma equipe de acompanhamento e controle da manutenção de uma distribuidora de energia elétrica do sul do Brasil. Dissertação (Mestrado em Engenharia de Produção)-PPGEP/UTFPR, Ponta Grossa, 2008.

SILVERTHORNE, C.; WANG, T.-H. Situational leadership style as a predictor of success and productivity among Taiwanese business organizations. Journal of Psychology, v. 135, n. 4, p. 399-412, 2001. http://dx.doi. org/10.1080/00223980109603707

SIMS JUNIOR, H. P.; FARAJ, S.; YUN, S. When should a leader be directive or empowering? How to develop your own situational theory of leadership. Kelley School of Business, Indiana University, 2008.

SOT0, E. Comportamento organizacional. São Paulo: Thomson, 2002.

TOOR, S. R.; OFORI, G. Leadership for future construction industry: agenda for authentic leadership. International Journal of Project Management, v. 26 n. 6, p. 620-630, 2008. http://dx.doi.org/10.1016/j.jproman.2007.09.010

WEATHERSBY, G. B. Leadership vs. management. Management Review, v. 88, p. 5, 1999.

\title{
Situational leadership in project management: a literature review
}

\begin{abstract}
The leadership style that should be adopted by a project manager is a subject that has been emphasized in recent researches. Among several theories, the situational leadership presented by Hersey and Blanchard (2007) approaches working and psychological maturity as elements that influence the performance of employees. The determination of such level allows the use of an adjustable style of leadership. This article approaches the necessity of using a tool that efficiently assists the project manager to adopt an adjustable style of leadership for the situation. In order to demonstrate how difficult such an activity can be, a research in an Information Technology company was fulfilled, evaluating the level of maturity. It was observed that, in order to practice a more effective leadership, it is necessary to count on more structuralized methods.
\end{abstract}

\section{Keywords}

Leadership style. Situational leadership. Project manager. 